Article

\title{
Surface Analysis and Optical Properties of Cu-Doped ZnO Thin Films Deposited by Radio Frequency Magnetron Sputtering
}

\author{
Guo-Ju Chen ${ }^{1}$, Sheng-Rui Jian ${ }^{1, *}$ and Jenh-Yih Juang ${ }^{2}$ \\ 1 Department of Materials Science and Engineering, I-Shou University, Kaohsiung 840, Taiwan; \\ gjchen@isu.edu.tw \\ 2 Department of Electrophysics, National Chiao Tung University, Hsinchu 300, Taiwan; \\ jyjuang@g2.nctu.edu.tw \\ * Correspondence: srjian@gmail.com; Tel.: +886-7-657-7711 (ext. 3130)
}

Received: 19 June 2018; Accepted: 29 July 2018; Published: 31 July 2018

check for updates

\begin{abstract}
In this study, $\mathrm{Cu}$-doped $\mathrm{ZnO}(\mathrm{CZO})$ thin films were grown on glass substrates by using the radio frequency magnetron sputtering technique. The effects of $\mathrm{Cu}$ doping on the structural, surface morphological, optical properties, and wettability behaviors of $\mathrm{CZO}$ thin films were investigated by $\mathrm{X}$-ray diffraction (XRD), atomic force microscopy (AFM), UV-Visible spectroscopy, and contact angle measurement, respectively. The XRD results indicated that all CZO thin films were textured, having a preferential crystallographic orientation along the hexagonal wurtzite (002) axis. The average transmittance in the visible wavelength region was above $80 \%$ for all CZO thin films. The optical band gap of the CZO films decreased from 3.18 to $2.85 \mathrm{eV}$ when the $\mathrm{Cu}$-doping was increased from $2 \%$ to $10 \%$. In addition, the water contact angle measurements were carried out to delineate the $\mathrm{Cu}$-doping effects on the changes in the surface energy and wettability of the films.
\end{abstract}

Keywords: Cu-doped ZnO thin film; XRD; AFM; UV-Vis; surface energy

\section{Introduction}

$\mathrm{ZnO}$ is a II-VI semiconductor with a direct wide band gap (3.37 eV) and the large exciton binding energy $(60 \mathrm{meV})$ at room temperature, which has been extensively investigated in a variety of applications for optoelectronics, solar cells, transparent thin film transistors, and biosensors [1-5]. Using the doping technique, the physical properties of $\mathrm{ZnO}$ can be significantly enhanced. However, $\mathrm{ZnO}$ usually behaves as a native n-type semiconductor and is known to be difficult to make it a p-type. Therefore, extensive research has been devoted to fabricating p-type $\mathrm{ZnO}$ thin films without much success.

The p-type doping in $\mathrm{ZnO}$ with various ions have been reported by either Group IA elements (substitute for $\mathrm{Zn}$ sites) or Group V elements (substitute for O sites) [6]. Since the ionic radii of Group IA elements are usually much smaller than that of $\mathrm{Zn}$, it is difficult to produce p-type materials [7]. In the face of these issues of reliability and reproducibility [8], the Group V elements are not an appropriate candidate because the origin of p-type may not be a direct substitution of them on the $\mathrm{O}$ sites. Considering the limitations of the elements of Group IA and Group V, transition metals have been used as dopants in $\mathrm{ZnO}$ [9-14] to enhance the optical properties and electrical conductivity, and to modify the energy band of $\mathrm{ZnO}$ thin films. Among them, the $\mathrm{Cu}$ element has an almost equal ionic radius to $\mathrm{Zn}^{2+}(0.74 \AA)$ [15], and the similar electronic shell structure between $\mathrm{Cu}$ and $\mathrm{Zn}$ is a further advantage for it to be the most suitable doping material. Previous $X$-ray photoelectron spectroscopy (XPS) study has also indicated that $\mathrm{Cu}$ ions are oxidized in the $\mathrm{ZnO}$ structure and substitute into the $\mathrm{ZnO}$ lattice at the $\mathrm{Zn}^{2+}$ site [11]. 
On the other hand, the performance of the surface is of the same importance since it is a critical characteristic for determining the practicability in outdoor applications of ZnO-based devices. A surface with a low free energy can reduce the adhesion of airborne contaminants and then be effectively removed by the rolling drops due to the hydrophobic behaviors [16], therefore, improving the environmental durability of thin films. Unfortunately, to date, only limited literature is available that explores the wettability properties of $\mathrm{Cu}$-doped $\mathrm{ZnO}(\mathrm{CZO})$ thin films [17]. In addition, the hydrophobic surface has been one of the critical, necessitated factors in many optoelectronic device applications [18-20]. Consequently, the hydrophobic or hydrophilic behavior of the CZO films' surface is also of great importance in realizing the designed functionality for device applications.

To date, several methods for preparing CZO thin films have been developed, such as the sol-gel method [21], molecular beam epitaxy [22], pulsed laser deposition [23], atomic layer deposition [24], and radio frequency magnetron sputtering [25]. Among them, the radio frequency magnetron sputtering method has been widely used for fabricating oxide thin films because of its advantages of relatively high deposition rates, low cost, easy control, and high efficiency for growing thin films of a good quality.

In this study, the effects of Cu-doping concentration on the structures, surface morphological features, and optical properties of CZO films deposited on glass substrates by radio frequency magnetron sputtering were investigated using X-ray diffraction (XRD), atomic force microscopy (AFM), and UV-Visible spectroscopy, respectively. In addition, the wettability characteristics and surface energy of CZO thin films are also discussed.

\section{Materials and Methods}

The CZO thin films used in this study were deposited on Coring 1737 glass substrates by radio frequency magnetron sputtering at $200{ }^{\circ} \mathrm{C}$ for $30 \mathrm{~min}$. Three $\mathrm{CuO}$ doped $\mathrm{ZnO}$ targets, namely $2 \%$, $6 \%$, and $10 \%$, respectively, were used. The base pressure of the sputtering chamber was less than $6.66 \times 10^{-4} \mathrm{~Pa}$. The working pressure was fixed at $6.66 \times 10^{-1} \mathrm{~Pa}$, with the sputtering power being kept at $100 \mathrm{~W}$ during film growth. The thickness of CZO thin films was about $200 \mathrm{~nm}$.

The crystal structure of CZO thin films was analyzed by X-ray diffraction (Panalytical X'Pert XRD, $\mathrm{Cu} \mathrm{K} \alpha, \lambda=0.154 \mathrm{~nm}$, PANalytical, Almelo, the Netherlands) by the grazing incidence technique at an incident angle of $1^{\circ}$. The compositions of the $\mathrm{CZO}$ films were confirmed by $\mathrm{X}$-ray photoelectron spectroscopy (XPS, JEOL JAMP-9500F, JEOL, Tokyo, Japan). The measured compositions of CZO films were very close to those designed for the targets, as shown in Table 1. Therefore, we quote the doping concentration in each film with the original $\mathrm{Cu}$ doping concentration designed for $\mathrm{CZO}$ targets used. The surface morphologies and the root-mean-square of average surface roughness $\left(R_{\mathrm{rms}}\right)$ of $\mathrm{CZO}$ thin films were examined by using an atomic force microscopy (AFM, Topometrix-Accures-II, TopoMetrix Crop., Santa Clara, CA, USA). The optical transmittance properties of CZO thin films were measured by using a Shimadzu UV-2450 UV-Vis spectrophotometer (Shimadzu, Kyoto, Japan). In addition, the wettability of CZO thin films' surface under ambient conditions was monitored using a Ramehart Model 200 contact angle goniometer (Ramé-hart, Succasunna, NJ, USA) with deionized water as the liquid at room temperature.

Table 1. The composition of CZO thin films measured by X-ray photoelectron spectroscopy (XPS).

\begin{tabular}{ccccc}
\hline Sample & Cu (at \%) & Zn (at \%) & O (at \%) & Stoichiometry of Cu \\
\hline $2 \%$ & 1.1 & 47.96 & 50.94 & 0.022 \\
$6 \%$ & 3.31 & 46.32 & 50.37 & 0.067 \\
$10 \%$ & 5.48 & 43.24 & 51.28 & 0.112 \\
\hline
\end{tabular}




\section{Results}

The XRD patterns of CZO thin films with various $\mathrm{Cu}$-doping concentrations of $2 \%, 6 \%$, and $10 \%$ are shown in Figure 1. The XRD results reveal that all $\mathrm{CZO}$ thin films have a wurtzite structured crystalline ZnO (JCPDS 36-1451) and have a significant (002) preferred orientation, which has been confirmed by a previous study [17]. No other phases corresponding to metal copper, oxides, or binary zinc copper were observed, indicating that $\mathrm{Cu}$-doping is uniform and does not alter the hexagonal wurtzite structure of $\mathrm{ZnO}$ films. It is noted that the intensity of (002)-peak was enhanced dramatically when the $\mathrm{Cu}$-doping concentration was increased from $2 \%$ to $6 \%$. However, further increasing of the $\mathrm{Cu}$-doping concentration up to $10 \%$ reduced the intensity of the (002)-peak, suggesting that excessive $\mathrm{Cu}$-doping can degrade the (002) preferential orientation of CZO thin films. The crystalline size of CZO thin films was evaluated using the full-width at half-maximum (FWHM) of the (002)-peak according to Scherrer's equation [26]:

$$
D=0.9 \frac{\lambda}{\beta \cos \theta}
$$

where $D$ is the crystalline size, $\lambda$ is the wavelength of the $\mathrm{X}$-ray radiation $(\mathrm{Cu} \mathrm{K} \alpha, \lambda=1.5406 \AA), \theta$ is the Bragg angle, and $\beta$ is the line width of the (002) diffraction peak, respectively. Since broadening of diffraction lines may arise from the instrumental broadening and from the crystal size, structural defects, and residual strain of materials. The measured instrumental broadening of about $0.152^{\circ}$, by a Si standard sample, was then subtracted from the raw data while performing the crystallite size calculation. The derived crystalline size indicated that it increases from 20 to $50 \mathrm{~nm}$ and then decreases to $29 \mathrm{~nm}$ with the $\mathrm{Cu}$-doping concentration of $2 \%, 6 \%$, and $10 \%$, respectively.

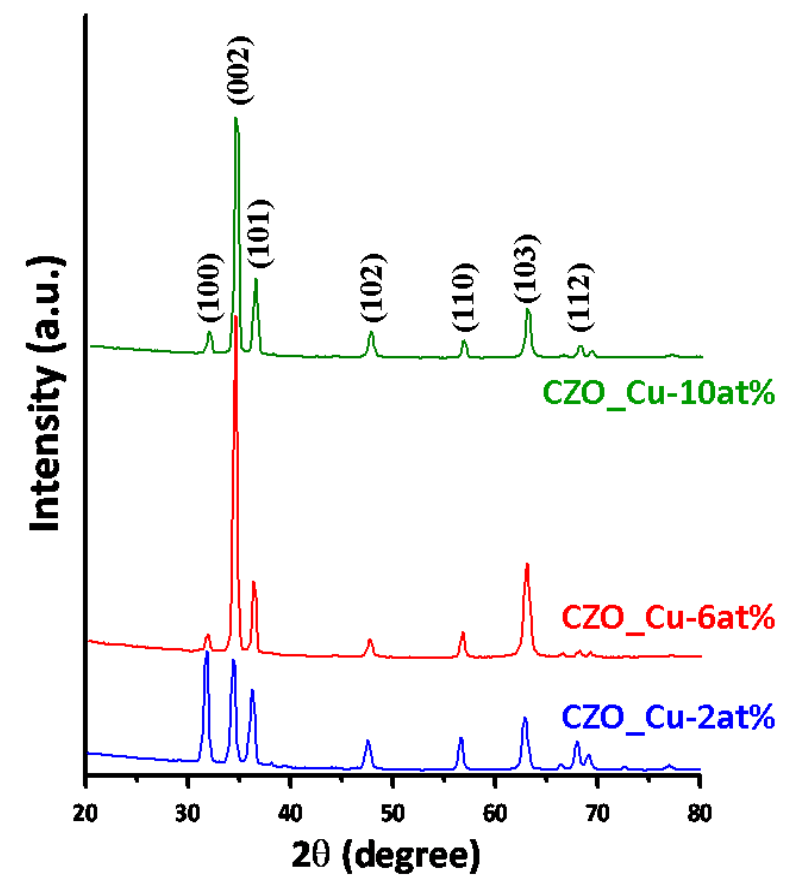

Figure 1. X-ray diffraction (XRD) patterns of CZO thin films deposited on glass substrates with various $\mathrm{Cu}$-doping concentrations.

Moreover, in Figure 1, the diffraction angle of the (002) diffraction peak is found to shift to a higher angle with increasing $\mathrm{Cu}$-doping concentrations, which suggests that the lattice constant $(c)$ of CZO thin films is decreased according to the Bragg's formula: 


$$
2 d \sin \theta=n \lambda \text { and } d^{2}=\left[\frac{4\left(h^{2}+k^{2}+h k\right)}{3 a^{2}}+\frac{l^{2}}{c^{2}}\right]^{-1}
$$

where $d$ denotes the crystalline plane distance of indices $(h, k, l)$. Since the $\mathrm{Cu}^{2+}$ ionic radius $(0.73 \AA)$ is smaller than that of the $\mathrm{Zn}^{2+}$ ion (0.74 $\AA$ ) [15], it is expected that substitutional doping of Cu should slightly shrink the $\mathrm{ZnO}$ lattice and cause the (002)-peak to shift to a higher angle. From the obtained results, one may further estimate the induced stress in the CZO thin films using the following formula:

$$
\sigma=-233 \frac{\left(c-c_{0}\right)}{c_{0}}
$$

where $c_{0}(=0.5205 \mathrm{~nm})$ is the lattice constant of $\mathrm{ZnO}$ film without defects. The obtained stresses were $0.2238,0.3581$, and $0.5819 \mathrm{GPa}$ for $\mathrm{Cu}-2 \%, \mathrm{Cu}-6 \%$, and $\mathrm{Cu}-10 \%$ doping in $\mathrm{CZO}$ thin films, respectively. Since the size of $\mathrm{Cu}^{2+}$ is smaller than that of the $\mathrm{Zn}^{2+}$, the resultant stresses are tensile.

The surface morphologies of CZO thin films revealed by AFM observations are shown in Figure 2. It can be seen that the $\mathrm{CZO}$ thin films all exhibit dense and homogenous microstructures. The AFM analysis of the $\mathrm{CZO}$ thin films showed that the $R_{\mathrm{rms}}$ of films increased from $\mathrm{Cu}-2 \%$ to $\mathrm{Cu}-6 \%$ because of the increase in crystalline size. As a result, the film surface of the $\mathrm{Cu}-6 \%$ sample was also rougher. The $R_{\text {rms }}$ of each respective CZO thin film is also displayed in Figure 2.

(a)

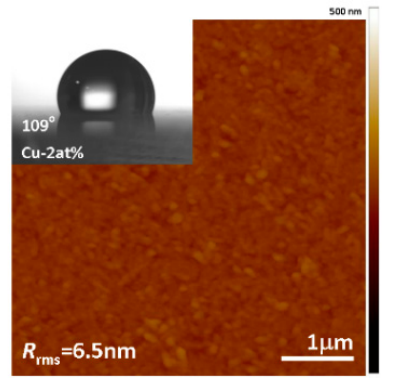

(b)

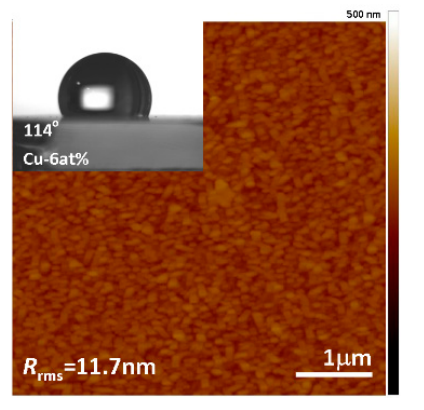

(c)

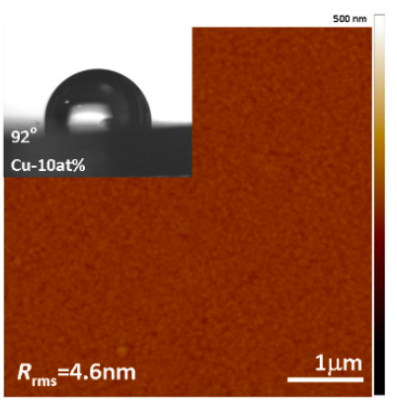

Figure 2. atomic force microscopy (AFM) surface micrographs $\left(5 \times 5 \mu \mathrm{m}^{2}\right)$ of CZO thin films with various Cu-doping concentrations (a) 2\%, (b) 6\%, and (c) 10\%. Inset: The corresponding water contact angles.

The wettability behavior of the surface is strongly related to the surface morphology of the sample surface [27]. The results of wettability tests are shown in the inset of Figure 2a-c. With an increasing

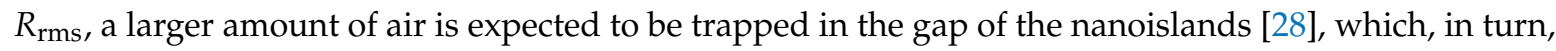
would greatly increase the contact area of the air-water interface (i.e., preventing the water droplets from penetrating into the air pockets), resulting in a larger contact angle $\left(\theta_{C A}\right)$, as displayed in the rougher sample (see the $\mathrm{Cu}-6 \%$ doping $\mathrm{CZO}$ thin film in Figure $2 \mathrm{~b}$ ). It is noted that similar phenomena were reported by Dave et al. [29].

In general, the surface wettability is a measure of the surface energy and is most commonly quantified by $\theta_{\mathrm{CA}}$ [18]. The surface energy for CZO thin films was calculated using the Fowkes-Girifalco-Good (FGG) theory [30]. According to the analysis of the FGG method, the considered critical interaction is the dispersive force or the van der Waals force across the interface existing between the water droplet and the solid surface. The FGG equation is given as:

$$
\gamma_{l s}=\gamma_{s}+\gamma_{l}-2 \sqrt{\gamma_{s}^{d} \gamma_{l}^{d}}
$$

where $\gamma_{l}^{d}$ and $\gamma_{s}^{d}$ are the dispersive portions of the surface tension for the liquid and solid surfaces, respectively. Using the Young's equation [18] combined with Equation (4) and employing 
nonpolar liquid deionized water $\left(72.8 \mathrm{~mJ} \cdot \mathrm{m}^{-2}\right)$ as a testing liquid, $\gamma_{l}^{d}$ is equal to $\gamma_{l}$, and the Girifalco-Good-Fowkes-Young equation becomes:

$$
\gamma_{s}^{d}=\frac{1}{4} \gamma_{l}\left(\cos \theta_{C A}+1\right)
$$

where $\gamma_{s}^{d}$ is the surface energy of the calculated materials. Hence, by straightforward analyses, the values of the surface energy obtained for CZO thin film were $12.3,10.8$, and $17.5 \mathrm{~mJ} \cdot \mathrm{m}^{-2}$, respectively, for $2 \%, 6 \%$, and $10 \% \mathrm{Cu}$-doping concentrations. Previous studies have indicated that the surface roughness is directly proportional to the contact angle and thereby inversely proportional to the surface energy of $\mathrm{ZnO}$ films [31,32]. Our results, nevertheless, are similar to that reported by Sapkal et al. [33]. In their work, the intensity of the (002) peak was significantly improved by an optimal Ag-doping concentration of $\sim 3 \%$ in $\mathrm{ZnO}$ films, which evidently led to a larger $\theta_{\mathrm{CA}}$ value. Based on these observations, it appears that the surface roughness and crystallinity of $\mathrm{CZO}$ thin films are the two main factors governing the surface wettability. In our case, an optimal doping concentration of $\mathrm{Cu}$ $(\sim 6 \%)$, seems to result in similar behaviors observed by Sapkal et al. [33]. Namely, the surface becomes much more hydrophobic (i.e., much lower surface energy) when the $\mathrm{ZnO}$ films are properly doped with $\mathrm{Cu}$.

The optical transmittance spectra of $\mathrm{CZO}$ thin films with various $\mathrm{Cu}$-doping concentrations of $2 \%$, $6 \%$, and $10 \%$ are displayed in Figure 3. As can be seen, the transmittance values are varied between $70 \%$ to $90 \%$ in the visible region $(400-800 \mathrm{~nm})$. It is clear from the transmittance spectra that the transparency has decreased with an increasing $\mathrm{Cu}$-doping concentration, which is consistent with previous studies [34,35].

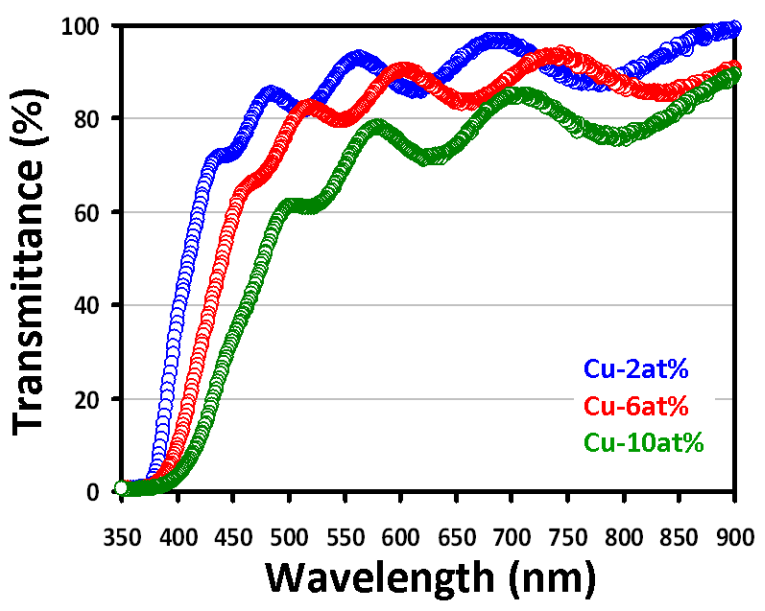

Figure 3. UV-Vis transmittance spectra of $\mathrm{CZO}$ thin films with various $\mathrm{Cu}$-doping concentrations.

The influence of $\mathrm{Cu}$-doping concentrations on the optical band gap $\left(E_{\mathrm{g}}\right)$ of $\mathrm{CZO}$ thin films can be further estimated from Figure 3. The $E_{\mathrm{g}}$ is calculated from transmittance data by using the Tauc equation:

$$
\alpha h v=A\left(h v-E_{g}\right)^{n}
$$

where $\alpha$ is the absorption coefficient, $h v$ is the photon energy, $A$ is the constant, and $n$ is an index. The index, $n$, can be 0.5 or 2 depending on whether it is a direct or indirect transition. Figure 4 shows a plot of the $(\alpha h v)^{2}$ versus the photon energy, which is linear at the absorption edge, confirming that the CZO films have a direct band gap. The value of the band gap is estimated by extrapolation of the straight line to the linear part to intersect the photon energy axis at $E_{\mathrm{g}}$ values. In the inset of Figure 4, it can be observed that the $E_{\mathrm{g}}$ of $\mathrm{Cu}-2 \% \mathrm{CZO}$ film is $3.18 \mathrm{eV}$, while increasing the $\mathrm{Cu}$ concentration to $6 \%$ and $10 \%$ caused it to decrease to 3.02 and $2.85 \mathrm{eV}$, respectively. This is consistent with the XRD results 
because the tensile stress causes a red shift in the $E_{\mathrm{g}}$ values by increasing the $\mathrm{Cu}$-doping concentration in CZO thin films [36]. According to a previous study [37], the $\mathrm{Cu} 3 d$ orbital is much shallower than the $\mathrm{Zn} 3 d$ orbital. The strong $d-p$ coupling between $\mathrm{Cu}$ and $\mathrm{O}$ moves the $\mathrm{O} 2 p$ up, while a $\mathrm{Cu}$ atom occupies a $\mathrm{Zn}$ site in $\mathrm{ZnO}$, resulting in the narrowed direct band gap being exhibited. These facts may be related to the red shift of $E_{\mathrm{g}}$ values by $\mathrm{Cu}$-doping in $\mathrm{ZnO}$ thin films.

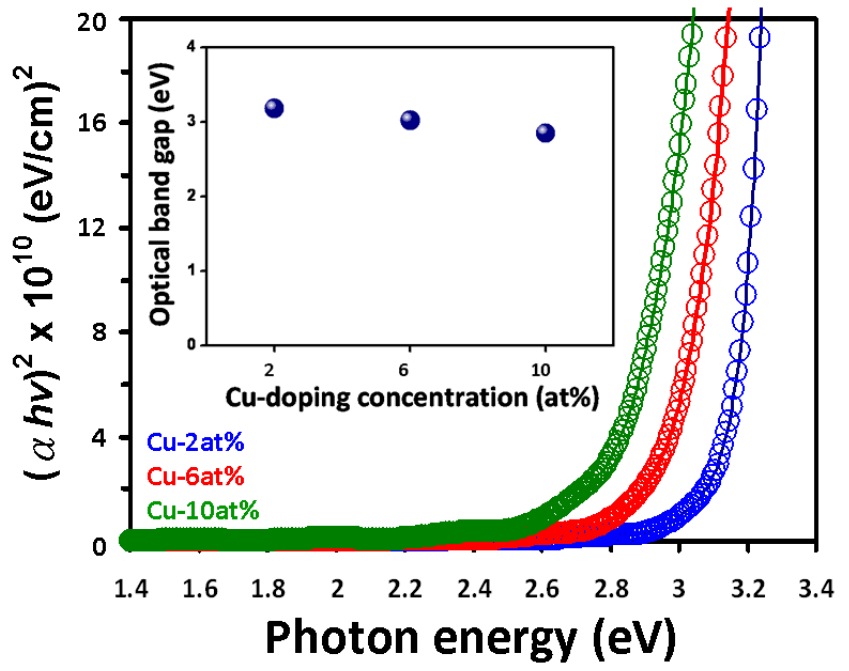

Figure 4. Plots of $(\alpha h v)^{2}$ versus photon energy of $\mathrm{CZO}$ thin films with various $\mathrm{Cu}$-doping concentrations. Inset: The evaluated optical band gap of CZO thin films.

\section{Conclusions}

In summary, we report the structural, surface morphological, optical, and wetting properties of $\mathrm{CZO}$ thin films with various $\mathrm{Cu}$-doping concentrations grown by radio frequency magnetron sputtering technique. $\mathrm{XRD}$ results indicated that $\mathrm{CZO}$ thin films had a hexagonal wurtzite structure and exhibited a (002)-preferred orientation. AFM observations showed that the surface morphological properties were changed via $\mathrm{Cu}$ doping and a larger crystalline size $(28 \mathrm{~nm})$ was presented in $\mathrm{Cu}-6 \%$ doping of CZO films. All CZO thin films exhibited a transmittance of over $80 \%$ in the visible wavelength range. Moreover, the optical energy band gap of CZO thin films shifted from 3.18 to $2.85 \mathrm{eV}$ with increasing $\mathrm{Cu}$-doping concentrations from $2 \%$ to $10 \%$. Combined with the contact angle measurement and theory calculation, all CZO thin films exhibited a low surface energy, resulting in hydrophobic behaviors.

Author Contributions: G.-J.C. contributed to the experiments and analyses. S.-R.J. and J.-Y.J. contributed to the discussion on materials characterizations. S.-R.J. designed the project of experiments and drafted the manuscript. All authors read and approved the final manuscript.

Funding: This research was funded by the Ministry of Science and Technology, Taiwan under Contract Nos., MOST104-2221-E-214-003, MOST105-2112-M-214-001, MOST106-2112-M-214-001 and MOST106-2221-E-214-014.

Acknowledgments: The authors thank H.-C. Tseng and C.-F. Wang for their technical support.

Conflicts of Interest: The authors declare no conflict of interest.

\section{References}

1. Chu, S.; Wang, G.; Zhou, W.; Lin, Y.; Chernyak, L.; Zhao, J.; Kong, J.; Li, L.; Ren, J.; Liu, J. Electrically pumped waveguide lasing from ZnO nanowires. Nat. Nanotechnol. 2011, 6, 506-510. [CrossRef] [PubMed]

2. Wang, C.F.; Ba, R.R.; Zhao, K.; Zhang, T.P.; Dong, L.; Pan, C.F. Enhanced emission intensity of vertical aligned flexible ZnO nanowire/p-polymer hybridized LED array by piezo-phototronic effect. Nano Energy 2015, 14, 364-371. [CrossRef] 
3. Liu, X.H.; Wang, H.Q.; Li, Y.R.; Gui, Z.Z.; Ming, S.Q.; Usman, K.; Zhang, W.J.; Fang, J.F. Regular Organic Solar Cells with Efficiency over 10\% and Promoted Stability by Ligand- and Thermal Annealing-Free Al-Doped ZnO Cathode Interlayer. Adv. Sci. 2017, 4, 1700053. [CrossRef] [PubMed]

4. Li, Y.; Yao, R.; Wang, H.H.; Wu, X.M.; Wu, J.Z.; Wu, X.H.; Qin, W. Enhanced Performance in Al-Doped ZnO Based Transparent Flexible Transparent Thin-Film Transistors Due to Oxygen Vacancy in ZnO Film with Zn-Al-O Interfaces Fabricated by Atomic Layer Deposition. ACS Appl. Mater. Interfaces 2017, 9, 11711-11720. [CrossRef] [PubMed]

5. Yeh, P.H.; Li, Z.; Wang, Z.L. Schottky-Gated Probe-Free ZnO Nanowire Biosensor. Adv. Mater. 2009, 21, 4975-4978. [CrossRef] [PubMed]

6. Park, C.H.; Zhang, S.B.; Wei, S.H. Origin of p-type doping difficulty in ZnO: The impurity perspective. Phys. Rev. B 2002, 66, 073202. [CrossRef]

7. Look, D.C.; Jones, R.L.; Sizelove, J.R.; Garces, N.Y.; Giles, C.N.; Halliburton, L.E. The path to ZnO devices: Donor and acceptor dynamics. Phys. Status Solidi A 2003, 195, 171-177. [CrossRef]

8. Look, D.C.; Clafin, B. P-type doping and devices based on ZnO. Phys. Status Solidi B 2004, 241, $624-630$. [CrossRef]

9. Shi, S.W.; He, G.; Zhang, M.; Song, X.P.; Li, J.L.; Wang, X.X.; Cui, J.B.; Chen, X.S.; Sun, Z.Q. Microstructural, Optical and Electrical Properties of Molybdenum Doped ZnO Films Deposited by Magnetron Sputtering. Sci. Adv. Mater. 2012, 4, 193-198. [CrossRef]

10. Lee, D.J.; Kim, K.J.; Kim, S.H.; Kwon, J.Y.; Xu, J.; Kim, K.B. Atomic layer deposition of Ti-doped ZnO films with enhanced electron mobility. J. Mater. Chem. C 2013, 1, 4761-4769. [CrossRef]

11. Liu, H.; Yang, J.; Hua, Z.; Zhang, Y.; Yang, L.; Xiao, L.; Xie, Z. The structure and magnetic properties of Cu-doped ZnO prepared by sol-gel method. Appl. Surf. Sci. 2010, 256, 4162-4165. [CrossRef]

12. Allabergenov, B.; Chung, S.H.; Jeong, S.M.; Kim, S.; Choi, B. Enhanced blue photoluminescence realized by copper diffusion doping of $\mathrm{ZnO}$ thin films. Opt. Mater. Express 2013, 3, 1733-1741. [CrossRef]

13. Ashokkumar, M.; Muthukumaran, S. Effect of Ni doping on electrical, photoluminescence and magnetic behavior of $\mathrm{Cu}$ doped $\mathrm{ZnO}$ nanoparticles. J. Lumin. 2015, 162, 97-103. [CrossRef]

14. Iikhechi, N.N.; Ghobadi, N.; Yahyavi, F. Enhanced optical and hydrophilic properties of V and La co-doped ZnO thin films. Opt. Quant. Electron. 2017, 49, 39. [CrossRef]

15. Wu, Z.F.; Wu, X.M.; Zhuge, L.J. Synthesis and magnetic properties of $\mathrm{Cu}$ doped ZnO nanorods via radio frequency plasma deposition. Appl. Phys. Lett. 2008, 93, 023103. [CrossRef]

16. Zimmermann, J.; Reifler, F.A.; Schrade, U.; Artus, G.R.J.; Seeger, S. Long term environmental durability of a superhydrophobic silicone nanofilament coating. Colloids Surf. A Physicochem. Eng. Asp. 2007, 302, $234-240$. [CrossRef]

17. Tyona, M.D.; Osuji, R.U.; Asogwa, P.U.; Jambure, S.B.; Ezema, F.I. Structural modification and band gap tailoring of zinc oxide thin films using copper impurities. J. Solid State Electrochem. 2017, 21, 2629-2637. [CrossRef]

18. Angelo, M.S.; McCandless, B.E.; Birkmire, R.W.; Rykov, S.A.; Chen, J.G. Contact wetting angle as a characterization technique for processing CdTe/CdS solar cells. Prog. Photovolt. 2007, 15, 93-111. [CrossRef]

19. Sun, H.; Luo, M.; Weng, W.; Cheng, K.; Du, P.; Shen, G.; Han, G. Room-temperature preparation of ZnO nanosheets grown on Si substrates by a seed-layer assisted solution route. Nanotechnology 2008, 19, 125603. [CrossRef] [PubMed]

20. Shinde, S.K.; Ghodake, G.S.; Dubal, D.P.; Lohar, G.M.; Lee, D.S.; Fulari, V.J. Structural, optical, and photo-electrochemical properties of marygold-like $\mathrm{CdSe}_{0.6} \mathrm{Te}_{0.4}$ synthesized by electrochemical route. Ceram. Int. 2014, 40, 11519-11524. [CrossRef]

21. Hashim, N.H.; Subramani, S.; Devarajan, M.; Ibrahim, A.R. Structural and surface characterization of undoped $\mathrm{ZnO}$ and $\mathrm{Cu}$ doped $\mathrm{ZnO}$ using sol-gel spin coating method. J. Mater. Sci. Mater. Electron. 2016, 27, 3520-3530. [CrossRef]

22. Suja, M.; Bashar, S.B.; Morshed, M.M.; Liu, J.L. Realization of Cu-Doped p-Type ZnO Thin Films by Molecular Beam Epitaxy. ACS Appl. Mater. Interfaces 2015, 7, 8894-8899. [CrossRef] [PubMed]

23. Shewale, P.S.; Yu, Y.S. UV photodetection properties of pulsed laser deposited Cu-doped ZnO thin film. Ceram. Int. 2017, 43, 4175-4182. [CrossRef] 
24. Xu, S.S.; Lu, H.L.; Zhang, Y.; Wang, T.; Geng, Y.; Huang, W.; Ding, S.J.; Zhang, D.W. Bandgap narrowing and conductivity evolution of atomic-layer-deposited $\mathrm{ZnO}: \mathrm{Cu}$ thin films under rapid thermal annealing. J. Alloys Compd. 2015, 638, 133-135. [CrossRef]

25. Sreedhar, A.; Kwon, J.H.; Yi, J.; Kim, J.S.; Gwag, J.S. Enhanced photoluminescence properties of Cu-doped $\mathrm{ZnO}$ thin films deposited by simultaneous RF and DC magnetron sputtering. Mater. Sci. Semcond. Process. 2016, 49, 8-14. [CrossRef]

26. Cullity, B.D.; Stock, S.R. Element of X-ray Diffraction; Prentice Hall: New Jersey, NJ, USA, 2001; p. 170.

27. Ottone, C.; Lamberti, A.; Cauda, V.; Fontana, M. Wetting Behavior of Hierarchical Oxide Nanostructures: $\mathrm{TiO}_{2}$ Nanotubes from Anodic Oxidation Decorated with ZnO Nanostructures. J. Electrochem. Soc. 2014, 161, D484-D488. [CrossRef]

28. Bayati, R.; Molaei, R.; Richmond, A.; Nori, S.; Wu, F.; Kumar, D.; Narayan, J.; Reynolds, J.G.; Reynolds, C.L. Modification of Properties of Yttria Stabilized Zirconia Epitaxial Thin Films by Excimer Laser Annealing. ACS Appl. Mater. Interfaces 2014, 6, 22316. [CrossRef] [PubMed]

29. Dave, V.; Gupta, H.O.; Chandra, R. Nanostructured hydrophobic DC sputtered inorganic oxide coating for outdoor glass insulators. Appl. Surf. Sci. 2014, 295, 231-239. [CrossRef]

30. Mahadik, D.B.; Rao, A.V.; Parale, V.G.; Kavale, M.S.; Wagh, P.B.; Ingale, S.V.; Gupta, S.C. Effect of surface composition and roughness on the apparent surface free energy of silica aerogel materials. Appl. Phys. Lett. 2011, 99, 104104. [CrossRef]

31. Chi, P.W.; Wei, D.H.; Wu, S.H.; Chen, Y.Y.; Yao, Y.D. Photoluminescence and wettability control of NiFe/ZnO heterostructure bilayer films. RSC Adv. 2015, 5, 96705-96713. [CrossRef]

32. Chao, C.H.; Chi, P.W.; Wei, D.H. Investigations on the Crystallographic Orientation Induced Surface Morphology Evolution of ZnO Thin Films and Their Wettability and Conductivity. J. Phys. Chem. C 2016, 120, 8210-8219. [CrossRef]

33. Sapkal, R.T.; Shinde, S.S.; Babar, A.R.; Moholkar, A.V.; Rajpure, K.Y.; Bhosale, C.H. Structural, Morphological, Optical and Photoluminescence Properties of Ag-Doped Zinc Oxide Thin Films. Mater. Express 2012, 2, 64-70. [CrossRef]

34. Ghosh, T.; Dutta, M.; Mridha, S.; Basak, D. Effect of Cu Doping in the Structural, Electrical, Optical, and Optoelectronic Properties of Sol-Gel ZnO Thin Films. J. Electrochem. Soc. 2009, 156, H285-H289. [CrossRef]

35. Saritha, A.C.; Shijeesh, M.R.; Vikas, L.S.; Prabhu, R.R.; Jayara, M.K. Growth and characterization of p-ZnO:Cu thin film and its homojunction application. J. Phys. D Appl. Phys. 2016, 49, 295105. [CrossRef]

36. Rao, T.P.; Kumar, M.C.S.; Angayarkanni, S.A.; Ashok, M. Effect of stress on optical band gap of ZnO thin films with substrate temperature by spray pyrolysis. J. Alloys Compd. 2009, 485, 413-417. [CrossRef]

37. Ahn, K.S.; Deutsch, T.; Yan, Y.; Jiang, C.S.; Perkins, C.L.; Turner, J.; Al-Jassim, M. Synthesis of band-gap-reduced $p$-type $\mathrm{ZnO}$ films by Cu incorporation. J. Appl. Phys. 2007, 102, 023517. [CrossRef] 